\title{
Electrical properties of photosensitive heterostructures $n-\mathrm{FeS}_{2} / p-\operatorname{InSe}$
}

\author{
I.G.Tkachuk ${ }^{1}$, I.G.Orletsky ${ }^{2}$, Z.D.Kovalyuk ${ }^{1}$, P.D.Marianchuk ${ }^{2}$ \\ ${ }^{1}$ Chernivtsi Division of I.Frantsevich Institute of Materials Science \\ Problems, 5 I.Vilde St., 58001 Chernivtsi, Ukraine \\ ${ }^{2}$ Y.Fedkovych National University of Chernivtsi, 2 Kotsubinsky Str., \\ 58012 Chernivtsi, Ukraine
}

Received February 20, 2018

\begin{abstract}
Conditions for production of photosensitive anisotypic $n-\mathrm{FeS}_{2} / p-\operatorname{lnSe}$ heterojunctions by the method of low-temperature spray-pyrolysis of thin films of pyrite on crystalline $p$-InSe substrates are studied. On the basis of analysis of temperature dependences of direct and reverse VACs (Volt-Ampere Characteristics), the dynamics of the change in energy parameters is established and the role of the energy states at the heterojunction boundary in formation of the contact potential difference is determined. A model of the energy diagram of the heterojunction is proposed, which describes well the electrophysical phenomena observed during the experiment. The mechanisms of formation of direct and return currents through the energy barrier of $n-\mathrm{FeS}_{2} / p-\operatorname{InSe}$ are determined.
\end{abstract}

Keywords: spray-pyrolysis, volt-ampere haracteristics, heterojunction, heterostructures.

Исследованы условия изготовления фоточувствительных анизотипных гетеропереходов $n-\mathrm{FeS}_{2} / p-\operatorname{lnSe}$ методом низкотемпературного спрей-пиролиза тонких пленок пирита на кристаллические подложки $p-\operatorname{InSe}$. На основании анализа температурных зависимостей прямых и обратных BAX изучена динамика изменения энергетических параметров и установлена роль энергетических состояний на границе гетероперехода при формировании контактной разности потенциалов. Предложена модель энергетической диаграммы, которая удовлетворительно коррелирует с экспериментально наблюдаемыми физическими явлениями на гетеропереходе. Определены механизмы токопереноса при прямом и обратном смещении гетероструктуры $n-\mathrm{FeS}_{2} / p-\operatorname{lnSe}$.

Електричні властивості фоточутливих гетероструктур $n-\mathrm{FeS}_{2} / p-\operatorname{lnSe}$. I.T.Tкачyк, І.Г.Орлецький, З.Д.Ковалюк, П.Д.Мар'янчук.

Досліджено умови виготовлення фоточутливих анізотипних гетеропереходів $n-\mathrm{FeS}_{2} / p-\operatorname{lnSe}$ методом низькотемпературного спрей-піролізу тонких плівок піриту на кристалічні підкладки $p$-InSe. На основі аналізу температурних залежностей прямих i зворотних ВАX встановлено динаміку зміни енергетичних параметрів та з'ясовано роль енергетичних станів на межі гетеропереходу при формуванні контактної різниці потенціалів. Запропоновано модель енергетичної діаграми гетеропереходу, яка добре корелює з експериментальними електрофізичними явищами. Визначено механізми формування прямого та зворотного струмів крізь енергетичний бар'єp $n-\mathrm{FeS}_{2} / p-\operatorname{lnSe}$.

\section{Introduction}

Indium mono selenide InSe has the band gap width of $E_{g}=1.2 \mathrm{eV}$, which is in the range of optimal values for photovoltaic transformation of the solar radiation spec- trum in terrestrial conditions. The layered structure of InSe crystals with the weak Van der Waals bonds between the layers provides their advantage over other semiconductors in manufacturing the substrates 
for heterostructures avoiding operations of ingot cutting, mechanical and chemical processing of the surface. The use of indium selenide as a base material allows the creation of photosensitive structures of various types: on the basis of the 'metalsemiconductor' contact [1], homotransitions $[2,3]$ and heterojunctions [4-6].

Iron disulfide $\mathrm{FeS}_{2}$ (pyrite) consists of the elements widespread in nature. Photosensitive structures based on $\mathrm{FeS}_{2}$ have been extensively studied lately [7-9]. Using the iron disulfide films with hole conductivity the straightening heterostructures $\mathrm{ZnO} / p-\mathrm{FeS}_{2}$ are manufactured [10], on the basis of $n-\mathrm{FeS}_{2}$, the $n-\mathrm{FeS}_{2} / \mathrm{M}$ Schottky diodes $(\mathrm{M}=\mathrm{Pt}$, Au, $\mathrm{Nb)}$ [11] and $p$-i-nZnO/FeS $/$ /Cul diodes are produced [12].

Thin $\mathrm{FeS}_{2}$ films produced by the method of spray-pyrolysis [13] are characterized by high resistance to the aggressive media exposure and have the bandgap width of $E_{g} \approx 1.25 \mathrm{eV}$ close to that of InSe. The peculiarity of their optical properties is the low light absorption coefficient in the longwavelength area through indirect optical transitions. For the radiation energies $h v \sim$ $2.2 \mathrm{eV}$, at which there is a direct absorption, the transmission coefficient of the films is more than $80 \%$. Such a feature of the optical properties of the thin $\mathrm{FeS}_{2}$ films creates the prospects of their application as a wide-band front layer in heterostructures.

In this research we present the results of the study of electrical properties and spectral photosensitivity of $n-\mathrm{FeS}_{2} / p-\operatorname{InSe}$ heterojunction produced by the method of lowtemperature spray-pyrolysis of pyrite thin films on $p-\operatorname{InSe}$ substrates.

\section{Experimental}

The $n-\mathrm{FeS}_{2} / p-\operatorname{InSe}$ structures were constructed using the indium selenide crystals of $p$-type conductivity grown by the Bridgman technique. The hole electrical conductivity was obtained by doping with an dope of cadmium $0.1 \%$ by weight. According to the data of the Hall effect study, the concentration of charge carriers and their mobility perpendicular to the axis of symmetry $C$ in InSe at temperature of $295 \mathrm{~K}$ were equal to $p \approx 10^{14} \mathrm{~cm}^{-3}$ and $\mu_{p H} \approx 50 \mathrm{~cm}^{2} /$ (B.c) respectively.

$\mathrm{FeS}_{2}$ films $\sim 0.5 \mu \mathrm{m}$ thick were applied on $p$-InSe substrates by the technique of low temperature spray-pyrolysis of $0.1 \mathrm{M}$ aqueous solutions of $\mathrm{FeCl}_{3} \cdot 6 \mathrm{H}_{2} \mathrm{O}$ and $\left(\mathrm{NH}_{2}\right)_{2} \mathrm{CS}$ salts with increased content of the

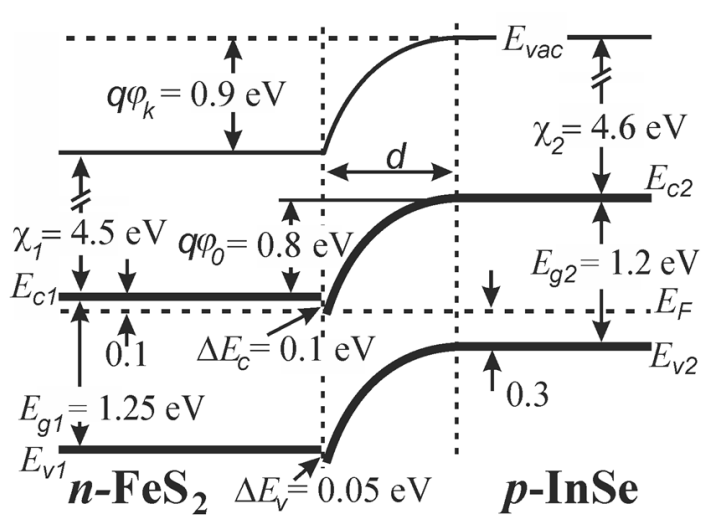

Fig. 1. Energy diagram of $n-\mathrm{FeS}_{2} / p-\operatorname{InSe}$ heterojunction $(T=300 \mathrm{~K})$.

component $\left(\mathrm{NH}_{2}\right)_{2} \mathrm{CS}$ characteristic of sulfide films obtained by this technique [1317]. To avoid significant thermal action on the $p-\operatorname{InSe}$ substrate, the pyrolysis temperature $T_{S}=280^{\circ} \mathrm{C}$ was chosen, which is in the range of minimum temperatures $(\sim 250-$ $300^{\circ} \mathrm{C}$ ) for obtaining the high-quality $\mathrm{FeS}_{2}$ films by the technique of spray-pyrolysis $[13,18]$. The films of pyrite obtained at this mode possessed a specific electrical conductivity $\sigma=1.0 \cdot 10^{-2} \Omega^{-1} \mathrm{~cm}^{-1}$ of $n$-type at $T=295 \mathrm{~K}$. The concentration of charge carriers in the $n-\mathrm{FeS}_{2}$ films is equal to $n=$ $1.8 \cdot 10^{17} \mathrm{~cm}^{-3}$, taking into account the Hall mobility, $\mu H=0.34 \mathrm{~cm}^{2} \mathrm{~B}^{-1} \mathrm{~s}^{-1}[19]$.

Contacts to the base material $p$-InSe and to the $n-\mathrm{FeS}_{2}$ film were formed using the conductive paste based on silver. Volt-ampere characteristics of the $n-\mathrm{FeS}_{2} / p-I n S e$ heterostructures were studied on the measuring complex SOLARTRON SI 1286, SI 1255 in the temperature range of $251<T<334 \mathrm{~K}$. Photoconductivity spectra of heterojunctions were measured at room temperature by a mono-chromatometer MDR-3 with resolution of $2.6 \mathrm{~nm} / \mathrm{mm}$. For the spectra, normalization was carried out with respect to the flux of photons.

\section{Results and discussion}

The obtained energy diagram (Fig. 1) was used to analyze the electrical properties of the $n-\mathrm{FeS}_{2} / p-3 \operatorname{lnSe}$ heterojunction. It is based on a model with no energy states at the interface and with conservation of the energy parameters of semiconductors (the affinity to electron $\chi$ and the band gap width $E_{g}$ ) at the contact boundary (the Anderson model) [20]. For construction of the energy diagram, the values of electron $\chi$ affinity $\left(\mathrm{FeS}_{2}\right)=4.5 \mathrm{eV}$ $[21,22], \chi(\operatorname{InSe})=4.55-4.6 \mathrm{eV}[23-26]$ and 
the band gap width $E_{g}(\operatorname{lnSe})=1.2 \mathrm{eV}$ were used [27]. The band gap width of thin films of $\mathrm{FeS}_{2}$ depends on the production conditions. The used value of $E_{g}\left(\mathrm{FeS}_{2}\right)=$ $1.25 \mathrm{eV}$ [13] corresponds to the experimental value under the conditions of low-temperature $\left(T_{S}=280^{\circ} \mathrm{C}\right)$ spray-pyrolysis, at which the $n-\mathrm{FeS}_{2} / p-\mathrm{InSe}$ heterojunctions were made.

Location of the Fermi level in the restricted zones relative of the bottom of the conduction band for $n-\mathrm{FeS}_{2}\left(\delta_{1}=0.1 \mathrm{eV}\right)$ and the valence band top $p$-InSe $\left(\delta_{2}=\right.$ $0.3 \mathrm{eV}$ ) were determined from the expressions for concentration of equilibrium charge carriers of non-degenerate semiconductors [28]:

$$
\begin{gathered}
E_{C}-E_{F}=\delta_{1}=k T \cdot \ln \left(\frac{2}{n} \cdot\left(\frac{2 \pi m_{n} k T}{h^{2}}\right)^{3 / 2}\right), \\
E_{F}-E_{V}=\delta_{2}=k T \cdot \ln \left(\frac{2}{p} \cdot\left(\frac{2 \pi m_{p} k T}{h^{2}}\right)^{3 / 2}\right)^{(2),}
\end{gathered}
$$

where $m_{n}=0.45 \cdot m_{0}$ [21], $\quad m_{p}=0.5 \cdot m_{0}$ [29] are effective electron masses in $\mathrm{FeS}_{2}$ and holes in InSe, respectively, $n$ and $p$ are concentrations of the main charge carriers in $n-\mathrm{FeS}_{2}$ and $p$-InSe, $E_{F}$ - the Fermi level position in the restricted zone.

Distribution of the spatial charge domain (SCD) between semiconductors on the heterojunction was determined by calculating the thickness of the regions in $\mathrm{FeS}_{2}$ and InSe depleted on the main charge carriers using expressions [30]:

$$
\begin{aligned}
& d_{n}=\sqrt{\frac{2 \varepsilon_{0} N_{A} \varepsilon_{n} \varepsilon_{p} \varphi_{k}}{q N_{D}\left(\varepsilon_{n} N_{D}+\varepsilon_{p} N_{A}\right)}}, \\
& d_{p}=\sqrt{\frac{2 \varepsilon_{0} N_{D} \varepsilon_{n} \varepsilon_{p} \varphi_{k}}{q N_{A}\left(\varepsilon_{n} N_{D}+\varepsilon_{p} N_{A}\right)}},
\end{aligned}
$$

where $q$ is the electron charge, $\varepsilon_{0}$ is the dielectric constant $\left(8.85 \cdot 10^{-12} \mathrm{~F} \cdot \mathrm{m}^{-1}\right), \varepsilon_{n}=$ 1.9 [31] and $N_{D}=n=1.8 \cdot 10^{17} \mathrm{~cm}^{-3}$ - the relative dielectric conductivity of donor concentration in $\mathrm{FeS}_{2}, \varepsilon_{p}=10.9$ [29] and $N_{A}=p=10^{14} \mathrm{~cm}^{-3}-$ dielectric conductivity and acceptor concentration in InSe, $q \varphi_{k}$ is the height of the potential barrier due to the contact potential difference. The calculated values of $d_{n}$ and $d_{p}$ are $1.8 \cdot 10^{-9} \mathrm{~m}$ and $3.27 \cdot 10^{-6} \mathrm{~m}$, respectively. The ratio of thickness of the depletion regions $d_{p} \gg d_{n}$ indicates to concentration of the SCD of $n-\mathrm{FeS}_{2} / p-\operatorname{InSe}$ heterojunctions in the $p-\operatorname{InSe}$ semiconductor.

According to the energy diagram of the $n-\mathrm{FeS}_{2} / p-$ InSe heterojunction, the energy barrier $q \varphi_{k}=0.9 \mathrm{eV}$ in the valence band for $p$-InSe holes is slightly greater than the energy barrier $q \varphi_{0}=0.8 \mathrm{eV}$ for electrons in the conduction band $n-\mathrm{FeS}_{2}$ (Fig. 1). Both electrons and holes can take part in the formation of direct and reverse current.

The study of VACs of the $n-\mathrm{FeS}_{2} / p-\operatorname{InSe}$ heterojunctions at direct and reverse voltages in the temperature range of $T=251-$ $334 \mathrm{~K}$ indicated the straightening properties of the structures. The perpendicular direction of the current to the layers plane of the crystal of the $p$-InSe base area in the $n-\mathrm{FeS}_{2} / p-$ InSe heterostructures results in a significant series resistance of $R_{s}$. The magnitude of this resistance depends on geometric dimensions of the $p-$ InSe substrate, and at decrease in the area of the heterojunction and significant thickness $(\sim 2 \mathrm{~mm})$ of the base area it can reach $R_{s} \sim 105 \Omega$. In the heterostructures studied, the series resistance $R_{S}$ was determined by cotangent of the inclination angle to the stress axis $\alpha\left(R_{S}\right.$ $=\operatorname{ctg} \alpha=\Delta V / \Delta I)$ of straight sections of the direct branches of the VAC at displacements $V>3 \mathrm{~V}\left(R_{S}=\operatorname{ctg} \alpha=\Delta V / \Delta I\right)$. Correct analysis of processes in the heterojunctions created on the materials with a significant specific resistance is possible if the voltage $V_{0}$ applied directly to the SCD of the junction without voltage drop component on the serial resistance $I \cdot R_{S}$. In this case, the VACs with direct displacement are described by the expression:

$$
I(V)=I_{s} \exp \left(\frac{e\left(V-I R_{S}\right)}{A k T}\right),
$$

where $V$ is the total voltage applied to the heterostructure, $I R_{s}$ is the voltage drop on series resistance of the structure, $A$ is the VAC nonideality coefficient.

The VAC of $n-\mathrm{FeS}_{2} / p-$ InSe heterojunctions in the temperature range of $T=251-$ $334 \mathrm{~K}$ at direct displacements constructed on the basis of expression (5) are shown in Fig. 2. The exclusion of the series resistance effect enabled to correctly determine the value of the energy barrier $\varphi_{0}$ in the $n-\mathrm{FeS}_{2} / p-$ InSe heterojunction by extrapolating the vertical (the condition of $R_{s} \rightarrow 0$ is satisfied) of the rectilinear regions of the direct VAC. The temperature dependence 


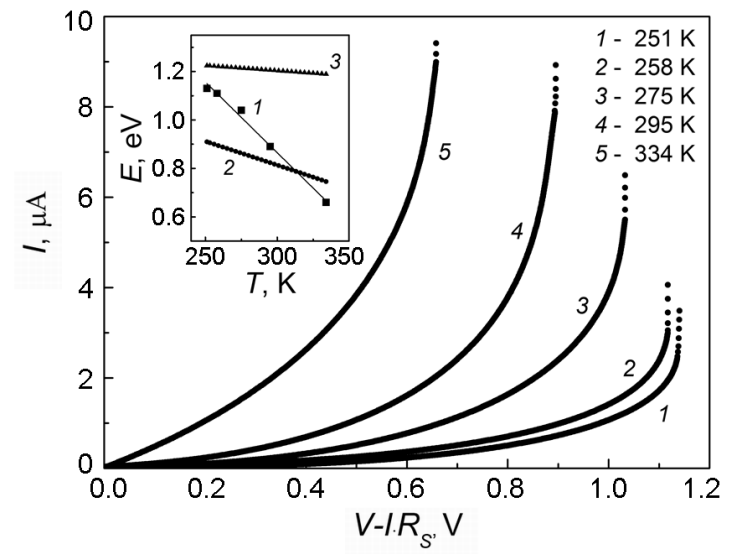

Fig. 2. Direct branches of VAC of $n-\mathrm{FeS}_{2} / p-$ InSe heterojunction at different temperatures, taking into account the voltage drop on the series resistance. (Insertion - experimental (1) and calculated (2) dependence of the height of potential barrier $\varphi_{0}$ in the heterojunction on temperature (3) - temperature dependence of the band gap width InSe).

$\varphi_{0} \exp =f(T)$ is shown in Fig. 2 (insertion). The experimentally determined rate of change of the height of a potential barrier with the temperature in the range of $T=251-334 \mathrm{~K}$ is $d\left(q \varphi_{0}{ }^{\exp }\right) / d T=-5.82 \cdot 10^{-3} \mathrm{eV} / \mathrm{K}$. It comes from the analysis of the energy diagram (Fig. 1) that the height of the potential barrier $q \varphi_{k}$ due to the contact potentials difference, the dependence on temperature is determined by the ratio.

The value $q \varphi_{0}$ is determined by the height of the potential barrier for electrons and lesser than the height of the barrier due to the contact potentials difference $q \varphi_{k}$ by the value of breakdown of conduction zones $\Delta E_{C}$ :

$$
q \varphi_{0}(T)=E_{g 2}(T)-k T \cdot \ln \left(\frac{N_{C} N_{V}}{n \cdot p}\right) .
$$

The rate of change in the height of the barrier for electrons determined by relation (6) taking into account the temperature coefficient of the change in width of the band gap InSe $\left.d E_{g} / d T\right\}=-4.2 \mathrm{eV} / \mathrm{K}$ [32] in the temperature interval of $T=251-334 \mathrm{~K}$ and the dependences on temperature of the main charge carriers concentration and the effective states densities in the permitted zones $N_{C}(T)$ and $N_{V}(T)$, is $d\left(q \varphi_{0}\right) / d T=-2.0 \cdot 10^{-3} \mathrm{eV} / \mathrm{K}$ (Fig. 2, insertion).

The observed difference between the experimental and calculated rate of change with temperature of the potential barrier height in the $n-\mathrm{FeS}_{2} / p-\operatorname{InSe}$ heterojunction is within one order and is explained by electrically active states at the interface between the semiconductors [33, 34], which arise as a result of discrepancy of the parameters of the crystal lattices $\mathrm{FeS}_{2}$ and p-InSe. The density of charge states $N_{S S}$ at the interface between the semiconductors is inversely proportional to the square of the distance between dislocations of the discrepancy $d\left(N_{S S} \approx d^{-2}\right)$, which is determined by the relation:

$$
d=\frac{a\left(\mathrm{FeS}_{2}\right) \cdot a(\operatorname{lnSe})}{a\left(\mathrm{FeS}_{2}\right)-a(\operatorname{lnSe})},
$$

where $a(\operatorname{lnSe})\}=4.002 \AA[32]$, and $a\left(\mathrm{FeS}_{2}\right)=$ $5.42 \AA$ [35] are the constants of crystalline lattices of InSe and $\mathrm{FeS}_{2}$, respectively. The calculated state density $N_{S S}=4.3 \cdot 10^{13} \mathrm{~cm}^{-2}$ is proportional to the $N_{S S}$ values for heterojunctions, in which there is a significant influence of the energy states on the properties [33, 34].

Change in the charge state of the energy states at the interface between the n$\mathrm{FeS}_{2} / p$-InSe heterojunctions affects the potential barrier height. With increase of temperature, these states are filled by electrons according to the Fermi-Dirac distribution, and a negative charge is localized in the heterojunction. Voltage of the electric field of this charge is oppositely directed to the field strength of the contact potentials difference, which is concentrated in the $p$-InSe semiconductor. According to the superposition principle, the total electric field in the SCD decreases and, consequently, a smaller experimental value of $\varphi_{0} \exp =0.66 \mathrm{~V}$ (at $T=334 \mathrm{~K})$ is observed compared with the calculated $\varphi_{0}=0.74 \mathrm{~V}$ (see Fig. 2, insertion). When the temperature decreases, the energy states in the heterojunction are released from the electrons; this leads to appearance of a positive charge $n$ in the heterojunction, the electric field of which is in line with the SCD field, and the contact potentials difference increases. With the decrease in temperature up to $T=251 \mathrm{~K}$, due to influence of the positively charged states, the greater value of $\varphi_{0} \exp =1.13 \mathrm{~V}$ is experimentally observed, compared with the calculated one based on the Anderson model $\varphi_{0}=0.91 \mathrm{~V}$ (at $T=251 \mathrm{~K}$ ). We can conclude from the analysis of the temperature dependences of the potential barrier height in the $n-\mathrm{FeS}_{2} / p-\operatorname{InSe}$ heterojunction (Fig. 2, insertion) that the influence of 

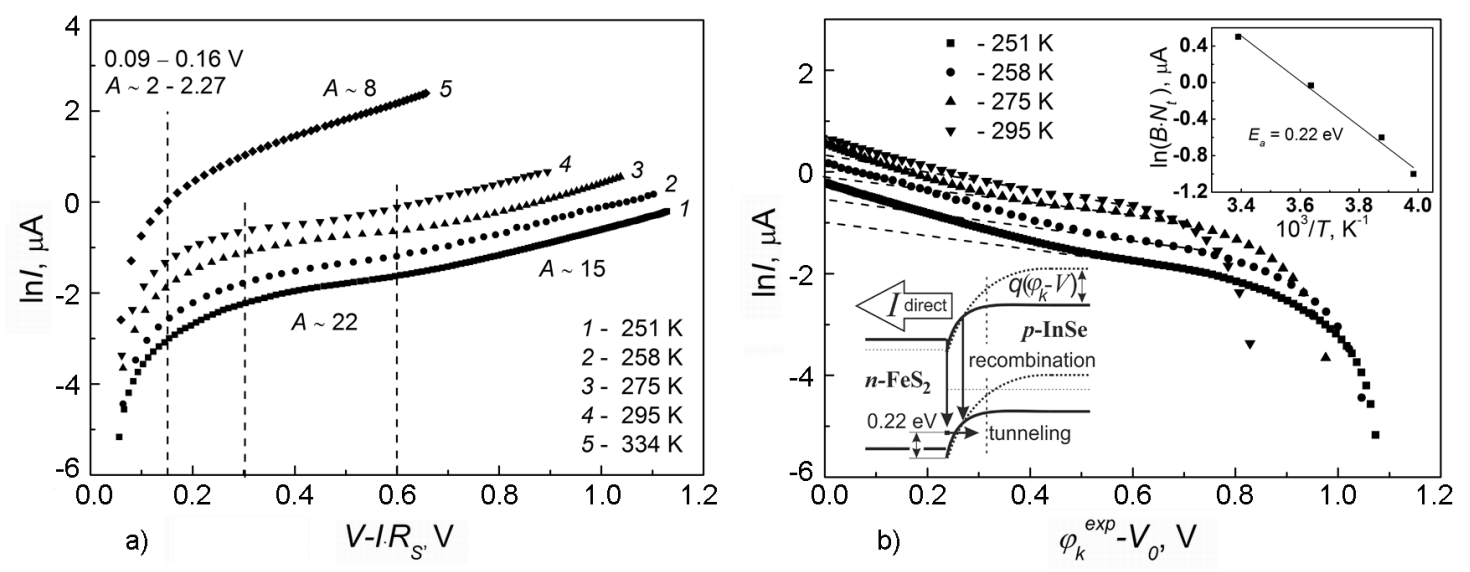

Fig. 3. a) Direct branches of $n-\mathrm{FeS}_{2} / p-\operatorname{lnSe}$ heterojunction VAC in half-logarithmic coordinates at different temperatures $T$ and dependence of series resistance on temperature (insertion). b) Determining the value of $\ln \left(B N_{t}\right)$ and activation energy $E_{a}$ of traps (insertion) on the boundary of $n-\mathrm{FeS}_{2} / p-\operatorname{InSe}$ heterojunction.

charge states on the value of $\varphi_{0}$ is not observed only within the temperature interval $T=310-320 \mathrm{~K}$. According to these conditions $\varphi_{0}=\varphi_{0}{ }^{\exp }=0.78 \mathrm{~V}$ and it is determined by difference between output of the materials and breakdown of the conduction band $\Delta E_{C}$. At room temperature, the energy barrier is formed by reduced by $\Delta E_{C}$ difference between the outputs and positive charge of the states at the boundary of the heterojunction. The value of $\varphi_{0}$ calculated according to the Anderson model at $T=$ $295 \mathrm{~K}$ is equal to $0.82 \mathrm{~V}$, (correspondingly, the contact potential difference $\varphi_{k}=$ $0.92 \mathrm{~V})$, while the experimentally observed one is $\varphi_{0}{ }^{\text {exp }}=0.89 \mathrm{~V}\left(\varphi_{k}{ }^{\text {exp }}=0.99 \mathrm{~V}\right)$.

To determine the mechanisms of forming direct currents of the heterojunction $n-\mathrm{FeS}_{2} / p-\operatorname{InSe}$, the VAC constructed in semilogarithmic scale $\ln I=f\left(V-I R_{s}\right)=$ $f\left(V_{0}\right)$ was used (Fig. 3a). At direct displacements $3 k T<q V_{0}<0.16 \mathrm{~V}$, the slope to the stress axis of dependences $\ln I=f\left(V_{0}\right)$ is characterized by the nonideality coefficient of the VAC $A=2-2.27$. With the decrease of the barrier height at the heterojunction up to value $q \varphi_{0}-0.16 \mathrm{eV}$ due to the direct displacement, the main mechanism of current formation is recombination of electrons in the SCD located in $p-I n S e$. At direct voltages $0.25<V_{0}<0.6$, the dependences $\ln I=$ $f\left(V_{0}\right)$ obtained within the temperature interval $T=251-295 \mathrm{~K}$ are characterized by the coefficient $A \approx 22$. Such great values of $A$ are observed in the $p-\mathrm{Ge} / n-\mathrm{Si}$ heterojunctions $(A=24.9-29.4)$ [30] with the energy profile of the zone diagram similar to that of $n-\mathrm{FeS}_{2} / p-$ InSe ones, and are the result of formation of direct currents by the transition of electrons to the states in the band gap at the boundary of the heterojunction and their further tunneling in the valence band of the $p$-type conductivity semiconductor. In the investigated $n-\mathrm{FeS}_{2} / p-\operatorname{InSe}$ structures, the transition of electrons to the states and their further tunneling in the valence band of $p-\operatorname{InSe}$ are most pronounced at the temperatures $T=251-295 \mathrm{~K}$ and the direct voltages up to $0.6 \mathrm{~V}$. At $V_{0}>0.6 \mathrm{~V}$, the coefficient $A \approx 15$, that indicates the mixed mechanism of current transfer - i.e. the transition of electrons to the states with further tunneling and recombination of electrons in the SCD. The first component of the current associated with tunneling is limited by the concentration of states at the boundary of the heterojunction and at $V_{0} \approx 0.6 \mathrm{~V}$ it turns to saturation. While increasing the direct voltage, the concentration of electrons displaced from $n-\mathrm{FeS}_{2}$ to the heterojunction increases, and some of them form a current due to recombination in the SCD.

For the dependence of $\ln I=f\left(V_{0}\right)$ of the heterojunction $n-\mathrm{FeS}_{2} / p-\operatorname{InSe}$ at the temperature $T=334 \mathrm{~K}$ (Fig. 3a) there is no region with clearly expressed tunnel component of the direct current. Within the voltage range $0.25<V_{0}<0.6 \mathrm{~V}$, the coefficient $A=8.3$. At the temperature increase up to $T=334 \mathrm{~K}$, the concentration of free states at the boundary of the heterojunction according to the Fermi-Dirac distribution decreases, thus the electronic transitions from the conduction band to these states and the 

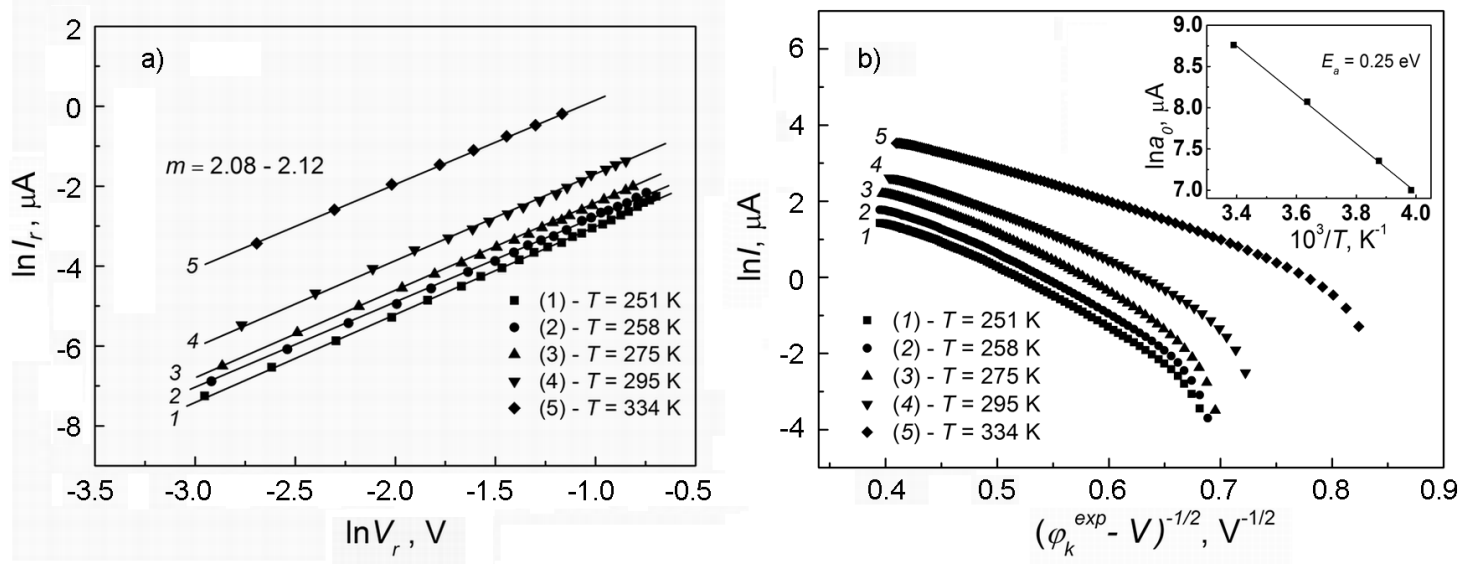

Fig. 4. a) Reverse branches of $n-\mathrm{FeS}_{2} / p-\operatorname{InSe}$ heterojunctions $\mathrm{VAC}$ at voltages $-0.5<V<0 \mathrm{~V}$. b) VAC of $n-\mathrm{FeS}_{2} / p-\operatorname{lnSe}$ heterojunction with inverse displacement $V_{r}>0.5 \mathrm{~V}$ at different temperatures $T$ and temperature dependence of $a_{0}$ parameter (insertion).

tunneling will also decrease. The recombination component of the direct current at $T=$ $334 \mathrm{~K}$ increases due to increase in the electrons concentration in $n-\mathrm{FeS}_{2}$. Decrease in the order of the series resistance of the $n-$ $\mathrm{FeS}_{2} / p-\mathrm{InSe}$ heterostructure with the increase of temperature from 251 to $334 \mathrm{~K}$ is characterized by activation energy $E_{a}=$ $0.21 \mathrm{eV}$, which is identical to the activation energy of the thin $\mathrm{FeS}_{2}$ films [13]. Resistance of the $p$-InSe substrates, according to the results of $\mathrm{TiN} / p-\ln S e$ structures study [4], does not change in the temperature range under study.

At capture of electrons by traps in the band gap zone at the interface between the heterojunction of $n-\mathrm{FeS}_{2} / p-\operatorname{InSe}$ and their further tunneling into the valence band $p$-InSe, the direct current is described by the expression [30]:

$$
I(V)=B N_{t} \exp \left[-\alpha\left(\varphi_{k}-V\right)\right]
$$

where $B$ - the constant, $N_{t}$ - concentration of traps in the band gap zone, $\alpha$ is the value which depends on the effective mass of electrons on the localized states in the band gap zone at the heterojunction boundary, dielectric conductivity and concentration of the acceptor impurity. Since the filling of electronic traps is determined by the Fermi-Dirac distribution function, $B N_{t}$ exponentially depends on the temperature, while the activation energy corresponding to the traps location relatively to the maximum height of the barrier for holes in the valence band can be found according to tangent of the inclination angle $\ln \left(B N_{t}\right)=$ $f(103 / T)$. The dependences $\ln I=f\left(\varphi_{k}-V_{0}\right)$ for determining $\ln \left(B N_{t}\right)$ and $\ln \left(B N_{t}\right)=$ $f(103 / T)$ by (8) are shown in Fig. 4. Extrapolation to ordinate axis was carried out on the VAC linear sections of the temperature range of $T=251-295 \mathrm{~K}$ with the most clearly defined tunnel component of the current, which corresponds to the maximum values of the coefficient $A$.

According to the determined activation energy $E_{a}=0.15 \mathrm{eV}$ (Fig. $3 \mathrm{~b}$, insertion), the traps that are occupied by the electrons of the conduction band at the heterojunction boundary and tunneled into the valence band of $p$-InSe are located $0.22 \mathrm{eV}$ above the peak of the energy barrier for holes.

The inverse branches of the $n-\mathrm{FeS}_{2} / p-\mathrm{InSe}$ heterojunction VAC at temperatures $T=$ $251-334 \mathrm{~K}$ in the range of voltages from $-(0.3-0.5)<V<0 \mathrm{~V}$ are described by the power law $I \sim V^{m}$ with the value of $m \approx 2$ (Fig. 4a). This dependence $I=f(V)$ is characteristic of the currents that are limited by spatial charge [36].

At the reverse voltages $V_{r}>\mathbf{0 . 3 -}$ 0.5) $\mathrm{V}$ the $n-\mathrm{FeS}_{2} / p-$ InSe heterojunction $\mathrm{VAC}$ is described by the expression [20]:

$$
I_{r e v}^{t}=a_{0} \exp \left(-b_{0}\left(\varphi_{k}^{\exp }-V\right)^{-1 / 2}\right),
$$

where $a_{0}$ is the parameter determined by probability of filling of the energy levels, from which the tunneling takes place, with the electrons, $b_{0}$ determines the rate of current change from that of voltage.

According to (9), the VAC in the coordinates $\ln I_{r e v}^{t}=f\left(\varphi_{k}{ }^{\exp }-V\right)^{-1 / 2}$ is linear 
(Fig. 4b). A slight decrease in inclination angle of the linear regions of the presented dependence at higher temperatures under study is related to the change in the effective density of states in the conduction band $n-\mathrm{FeS}_{2}$ to which the tunneling is carried out, and decrease in the width of the band gap zone of pyrite due to temperature increase. The temperature dependence of $a_{0}$ parameter enables to determine (in the first approximation $a_{0} \sim-E_{a} / k T$ [37]) the occurrence depth of the level in the band gap zone of $p-\operatorname{lnSe}$, from which the tunneling of electrons occurs. The value of $a_{0}$ is obtained by extrapolating the linear regions $\ln I_{r e v}^{t}=$ $f\left(\varphi_{k} e^{e x p}-V\right)^{-1 / 2}$ to ordinate axis. The location depth of the level determined from the temperature dependence in the range of 251 $<T<295 \mathrm{~K}$ of $a_{0}$ parameter (Fig. $4 \mathrm{~b}$, insertion), amounts to $0.25 \mathrm{eV}$ relative to the $p$-InSe valence band top. The obtained value agrees with the occurrence depth of $E_{A}=$ $0.25-0.26 \mathrm{eV}$ of the acceptor levels of the doped $\mathrm{Cd} p-\operatorname{InSe}$ [38]. The value of $a_{0}$ parameter at $T=334 \mathrm{~K}$ is lower than that for temperatures of $251<T<295 \mathrm{~K}$. This indicates that the levels with lesser probability of filling by electrons participate in the tunneling, that is, the levels that are located deeper in the bandgap than the acceptor ones $\left(E_{T}>E_{A}\right)$. Such deep levels in the indium selenide $\left(E_{T}=0.46-0.49 \mathrm{eV}\right)$ are created by the dope of Cd [38].

The spectral dependence of the quantum efficiency at illumination of the $n-\mathrm{FeS}_{2} / p-$ InSe heterostructure from the side of $\mathrm{FeS}_{2}$ film covers the photon energy range of 1.2 to $3.1 \mathrm{eV}$ with the maximum at $2.8 \mathrm{eV}$ (Fig. 5). The long-wave edge of photosensitivity corresponds to the energy of quanta of $1.2 \mathrm{eV}$ and is determined by the edge of fundamental absorption in $p-\ln S e$. The $n-\mathrm{FeS}_{2}$ film applied on $p-\operatorname{InSe}$ is a nondirect gap semiconductor [13] and light absorption in it at the energies slightly higher than the band gap $\left(E_{g}=1.25 \mathrm{eV}\right)$ is characterized by a small absorption coefficient $\alpha$ $10^{3} \mathrm{~cm}^{-1}$. At the quanta energy $h v=$ $1.5 \mathrm{eV}$, the absorption coefficient of $\mathrm{FeS}_{2}$ $\alpha \sim 10^{-4} \mathrm{~cm}^{-1}$ and $\sim 60 \%$ of radiation penetrates to the $n-\mathrm{FeS}_{2} / p-\mathrm{InSe}$ heterojunction boundary through the film with thickness $d=0.5 \mu \mathrm{m}$. The direct optical junctions with high $\alpha \sim 10^{5} \mathrm{~cm}^{-1}$ in $\mathrm{FeS}_{2}$ begin at absorption of quanta $h v \sim 2.2 \mathrm{eV}$. At the radiation energy $\sim 2.8 \mathrm{eV}$, which corresponds to the maximum of photoconductivity of the $n-\mathrm{FeS}_{2} / p-\operatorname{InSe}$ heterostructure,

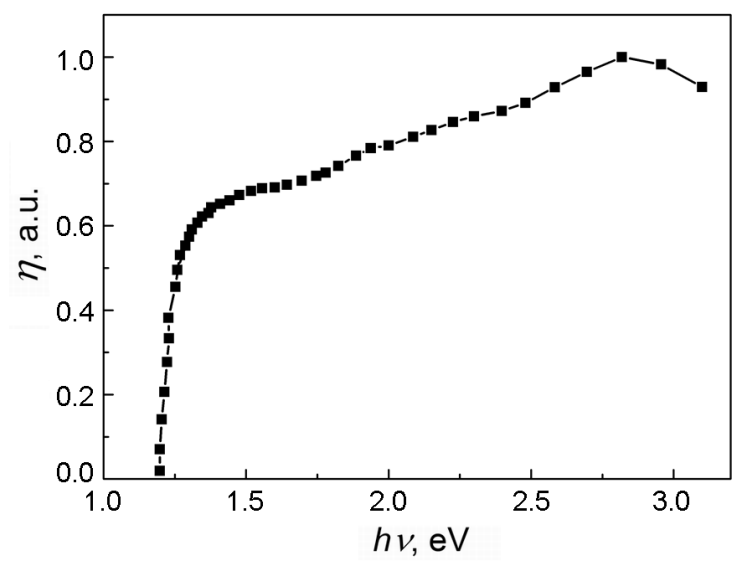

Fig. 5. Spectral dependence of relative quantum efficiency of $n-\mathrm{FeS}_{2} / p-\operatorname{lnSe}$ heterojunction.

the photogeneration of nonequilibrium charge carriers is completely concentrated in the $\mathrm{FeS}_{2}$ film. At irradiation by quantum energies $h v>2.8 \mathrm{eV}$, the region of the most intense generation of electron-hole pairs approaches to the frontal surface of $\mathrm{FeS}_{2}$, for which a high recombination rate is typical, and photosensitivity of the $n-\mathrm{FeS}_{2} / p-\operatorname{InSe}$ structures decreases. The total width of the spectrum of the relative quantum efficiency at the half-height $\delta_{1 / 2}$ is not less than 1.8 .

\section{Conclusions}

Photosensitive $n-\mathrm{FeS}_{2} / p-\operatorname{InSe}$ heterostructures were obtained by the technique of low-temperature spray pyrolysis of $\mathrm{FeS}_{2}$ films on the surface of $p$-InSe. The straightening properties of the structures are determined by the energy barrier $q \varphi_{0}=$ $0.89 \mathrm{eV}$ (at $T=295 \mathrm{~K}$ ) for electrons in the conduction band in the heterojunction, which differs from the contact potentials difference $\varphi_{k}=0.99 \mathrm{~V}$ due to distinction of the electron affinities of the contacting materials. The $n-\mathrm{FeS}_{2} / p-\operatorname{lnSe}$ heterojunction SCD is formed due to difference in the output works of the electron from the materials and partial influence of the charged states at the boundary of division. When direct voltages reach up to 0.16 , the current flows through the heterojunction due to recombination in the SCD, which is located in near-contact region from the side of $p-$ InSe. At direct displacements of $V>0.16$ the basic mechanism of current flow is to capture the electrons trapped at the heterojunction border (energy states by $0.22 \mathrm{eV}$ higher than the valence band peak) with further tunneling in the valence band of $p-I n S e$. The reverse current at the voltages 
up to $(0.3-0.5) \mathrm{V}$ is limited by the area of spatial charge of free charge carriers. Increase in the reverse voltage above $0.5 \mathrm{~V}$ leads to the tunneling of electrons from the energy levels of the $p-I n S e$ band gap. The wide spectrum of quantum efficiency of $n-$ $\mathrm{FeS}_{2} / p-\operatorname{InSe}$ heterostructures $1.2-3.1 \mathrm{eV}$ contributes to the prospect of their use as photoconductors of radiation energy, under the condition that the series resistance is reduced.

\section{References}

1. S.I.Drapak, V.B.Orletskii, Z.D.Kovalyuk, Techn. Phys. Let., 29, 480 (2003).

2. V.A.Khandozhko, Z.R.Kudrynskyi, Z.Kovalyuk, Semiconduct., 48, 545 (2014).

3. V.N.Katerinchuk, M.Z.Kovalyuk, Phys.Stat. Sol. (a), 25, 133 (1992).

4. I.G.Orletsky, M.I.Ilashchuk, V.V.Brus, Semiconduct., 50, 334 (2016).

5. Z.R.Kudrynskyi, Z.D.Kovalyuk, V.N.Katerynchuk, Act. Phys.Pol.A, 124, 720 (2013).

6. V.N.Katerynchuk, Z.R.Kudrynskyi, V.V.Khomyak, Semiconduct., 47, 943 (2013).

7. S.Middya, A.Layek, A.Dey, P.P.Ray, $J$. Mater. Sci. Technol., 30, 770 (2014).

8. L.Luo, W.Luan, B.Yuan, Energy Proc., 75, 2181 (2015).

9. S.Shukla, N.H.Loc, P.P.Boix, T.M.Koh, ACS Nano, 8, 10597 (2014).

10. S.Kawai, R.Yamazaki, S.Sobue, APL Materials, 2, 032110 (2014).

11. K.Buker, N.Alonso-Vante, H,Tributsch, $J$. Appl. Phys., 72, 5721 (1992).

12. Z.Yang, M.Wang, S.Shukla, Scient.Rep., 5, (2015).

13. I.G.Orletskii, P.D.Mar'yanchuk, E.V.Maistruk, Phys. Sol.Stat., 58, 37 (2016).

14. I.G.Orletskii, P.D.Maryanchuk, E.V.Maistruk, Inorg. Mater., 52, 851 (2016).

15. V.V.Brus, I.S.Babichuk, I.G.Orletskyi, Appl. Opt., 55, 158 (2016).
16. I.G.Orletskii, P.D.Mar'yanchuk, M.N.Solovan, Phys. Sol.Stat., 58, 1058 (2016).

17. I.G.Orletskii, P.D.Mar'yanchuk, M.N.Solovan, Tech.Phys. Lett., 42, 291 (2016).

18. C.T.Kao, J.B.Shi, H.W.Lee, F.C.Cheng, J. Therm. Spray Techn., 25, 580 (2016).

19. M.Morsli, A.Bonnet, L.Cattin, J.Phys.I France, 5, 699 (1995).

20. B.L.Sharma, R.K.Purohit, Semicond.Heteroj., 14, 451 (1974).

21. A.Ennaoui, H.Tributsch, Sol.Energy Mater., 27, 461 (1986).

22. G.W.Mudd, S.A.Svatek, L.Hague, $A d v$. Mater., 27, 3760 (2015).

23. F.Yan, L.Zhao, A.Patane, P.Hu, Nanotechnology, 28, 25 (2017).

24. M.K,L,Man, A.Margiolakis, S.Deckoff-Jones, Nat. Nanotech., 12, 36 (2016).

25. S.E.Al Garni, O.A.Omareye, A.F.Qasrawi, Optik - International Journal for Light and Electron Optics, 144, 340 (2017).

26. Z.D.Kovalyuk, O.N.Sydor, V.Katerinchuk, Semiconduct., 41, 1056 (2007).

27. S.M.Sze, K.Kwok, Phys.Semiconduct.Dev., 13, 19 (2007).

28. N.Kuroda, Y,Nishina, Sol.Stat.Commun., 34, 481 (1980).

29. A.G.Milnes, D.Feucht, New York and London: Academic Press), 27 , 36 (1972).

30. D.E.Husk, M.S.Seehra, Sol.Stat.Commun., 45, 1147 (1978).

31. O.Madelung, Semiconduct., 48, 23 (2007).

32. V.V.Brus, M.I.Ilashchuk, Z.D.Kovalyuk, Semiconduct., 85, 1077 (2011).

33. V.V.Brus, I.G.Orletsky, M.I.Ilashchuk, Semiconduct., 2, 1046 (2014).

34. Y.Xu, M.Schoonen, Americ.Miner., 5, 543 (2011).

35. A.Lampert Murray, P.Mark, Current Injection in Solids, 44, 24 (1970).

36. P.M.Gorley, Z.M.Grushka, V.P.Makhniy, Phys. Stat.Sol. (c), 44, 3622 (2008).

37. A.Segura, M.C.Martinez-Tomas, B.Mari, Apl. Phys.A, 34, 249 (2007). 